\title{
Recovery of olfactory function using intranasal natural honey after post-traumatic anosmia
}

\section{Introduction}

It has been estimated that approximately $3.7-75 \%$ of the general population suffers from olfactory dysfunction. Etiological factors include chronic craniofacial trauma, viral illness, rhino sinusitis, systemic disorders, neurological disorders and drugs. ${ }^{1}$ Head trauma is one of the most common etiologies behind olfactory loss. Depending on the severity of the head trauma, anosmia might occur in up to $30 \%$ of patients. Most patients with olfactory loss following trauma recover within two months. However, some patients may require much longer time to recover from post-traumatic olfactory loss. We present a rare case of recovery from anosmia seven months post initial trauma after using intranasal natural honey application.

\section{Case presentation}

We report the case of a 74-year-old Asian man who suffered complete anosmia from a severe head and nose trauma complicated by epistaxis following sudden fall to the ground after slipping on the steps without loss of consciousness. The patient is a known case of pre diabetes, obesity, hypertension and chronic heavy smoker. . Four weeks later post fall the patient started having a gradual hypogeusia, loosing (salty, sore and sweet sensation.) followed by complete hypogeusia and anosmia over one month period. One month Post fall he was seen by the ENT specialist at another primary health care center who prescribed him intranasal steroid impregnated gauze packing and anti-histamine tablets and instructed the patient to apply topical steroid lotion to his nasal mucosa on a daily basis for one month using a cotton bud. At follow up the patient reported no improvement .Consequently the patient quality of life significantly decreased. Subsequently he was referred to an ENT consultant at the secondary hospital who prescribed him prednisolone $30 \mathrm{mg}$ daily and cetirizine $10 \mathrm{mg}$ for one month along with intranasal mometasone spray along with a neurologist who ordered an MRI for the patient showing nasal septal deviation but no fracture or intracranial lesions. This approach also did not improve the patient sense of taste or smell. The patient was feeling down for 12 months and subsequently he visited a consultant family physician with special interest in the use of natural honey who suggested the use of intranasal application of natural honey as a last resort.

During the consultation the patient quality of life was assessed via asking him to fill in the Patient Health Questionnaire (PHQ-9) where he scored 16/24 denoting moderate depression. After signing an informed consent the patient was instructed to place the clear natural honey via a $20 \mathrm{ml}$ gauge syringe in a special modified" prayer to mecca" position or "Hashim position", (the fronto-parital bone of the cranium is touching the ground and the mental protuberance of the mandible is touching the sternum in a flexed neck position). The patient was asked to embrace that position for a total of 10minutes once daily over a four weeks period of time. The patient was counseled about the burning sensation of honey as it runs over the nasal and sinuses mucosal epithelial surfaces. The burning sensation is due to the acidic nature of natural honey. The natural honey used was an organic blossom honey imported from the UK (Wilkin\& Sons limited). In the two weeks follow up visit the patient has noticed a

\author{
Volume 10 Issue 3 - 2018
}

\author{
Zaid Alhamdanni, Badriya Al lenjawi, Hashim \\ Mohamed \\ Weill Cornell Medicine Qatar, Qatar
}

Correspondence: Hashim Mohamed,Weill Cornell Medicine Qatar,Al luqta street, Al rayan, Doha, Qatar, Tel +97455861008, Email fmcc2000@gmail.com

Received: May 30, 2017 | Published: May 29, 2018

dramatic improvement reaching $70 \%$. He was reassured and was asked to continue the same management for a further two weeks. At follow up the patient reported no problems with his sense of taste and smell and has normal flavor perception during eating and drinking but complained of the stinging sensation of honey during the first ten minutes after the intranasal application. Similarly his quality of life has improved dramatically with a score of $2 / 24$ denoting no depression.

\section{Discussion}

The prevalence of olfactory impairment varies widely, from 3.7\% to $75 \%$, depending the population studied and methodological designs employed. ${ }^{1}$ Nearly $5 \%$ to $20 \%$ of all patients attending secondary and tertiary care with olfactory dysfunction are labeled as suffering from post-traumatic disorders.

Excluding degenerative diseases, the most common causes of olfaction impairment are viral illnesses involving the upper respiratory tract $(18-45 \%$ of the clinical population), nasal/sinus disease (7$56 \%$ ), traumatic head injury ( $8-20 \%)$, toxins/drugs exposure $(2-6 \%)$, and congenital causes $(0-4 \%){ }^{2-4}$ Anosmia may occur in up to $30 \%$ of patients suffering from various degrees of head trauma. ${ }^{2}$

The exact mechanism behind olfactory dysfunction remains elusive although many mechanisms have been proposed. Laceration of the primary olfactory nerves due to shearing injury at the cribriform plate extending from the nasal cavity to the olfactory bulb are proposed to be one of the common etiologies seen in post-traumatic smell loss. Objective testing in previous studies in patients with post traumatic head injuries revealed a recovery rate in the range of $30 \%$ to $40 \%$, although true subjective improvement is demonstrated in only $10 \%$ of cases. ${ }^{3,4}$

Losing the sense of smell often imposes a multitude of emotional, psychological and practical challenges, thereby affecting employment status (eg. Chefs, natural gas workers, perfumeries, tea and coffee tasters and firefighters) who fail to appreciate odors and tastes. In a study conducted by ${ }^{5}$ in subjects with self-reported olfaction loss ,the prevalence of depression and reduced quality of life (QOL) was documented in over $20 \%$ of the respondents based on the SF- $36 .{ }^{5}$ Furthermore, et al., ${ }^{6}$ reported a prevalence of exhibition of signs of depression as high as $68 \%$ among patients with loss of smell.?

Detecting changes in the central nervous system provoked by olfactory stimulants is the only objective measurement of the sense of 
smell and is cumbersome to perform and usually reserved for research purposes or to assess olfaction in medico legal cases or non-compliant patients.

Direct visualization of central changes caused by olfactory stimulants is carried out by new techniques which include functional imaging (functional Positron Emission Tomography, functional Magnetic Resonance Imaging). Although these methods are currently reserved for scientific purposes they may become useful tools for clinical practice. ${ }^{8}$

Although trauma and shear pressure are known causes of anosmia, subtle inflammation of the nerve endings following trauma may be responsible for anosmia in some cases. Another possibility is that changes in the composition of the mucous covering the olfactory receptors could interfere with the ability of odorant molecules to reach or activate the receptors.

Damage to the olfactory neuro-epithelium causing sensori-neural impairment ${ }^{9}$ along with inflammation and edema are thought to be responsible for the loss of olfaction in our case, although the patient's age and his chronic smoking history are contributing factors.

Natural honey has unique actions including antiimmunomodulatory, antioxidant and antibacterial effects ${ }^{10,11}$. In their experimental study investigating the effect of aerosolised honey on histopathological changes of the airway in a rabbit model of ovalbumin (OVA)-induced asthma. ${ }^{12}$ Demonstrated histopathological evidence that aerosolised natural honey at $50 \%$ concentration resulted in structural repair of the epithelial, mucosal and sub mucosal linings of the bronchioles. Furthermore, Natural honey lead to a reduction of the number of airway inflammatory cells present in bronchoalveolar lavage fluid and inhibited goblet cell production hyperplasia, and mucus sectretion.

Bashkaran et al., ${ }^{13}$ examined the anti-inflammatory properties of Tualang honey in treating alkaline injury to the eyes of rabbits and reported that honey contained an anti-inflammatory component with an effectiveness comparable to that of conventional treatment. Manuka honey was reported to increase the expression of the antiinflammatory cytokines such as IL-10, IL-1ra, and growth factors PDG. ${ }^{14}$
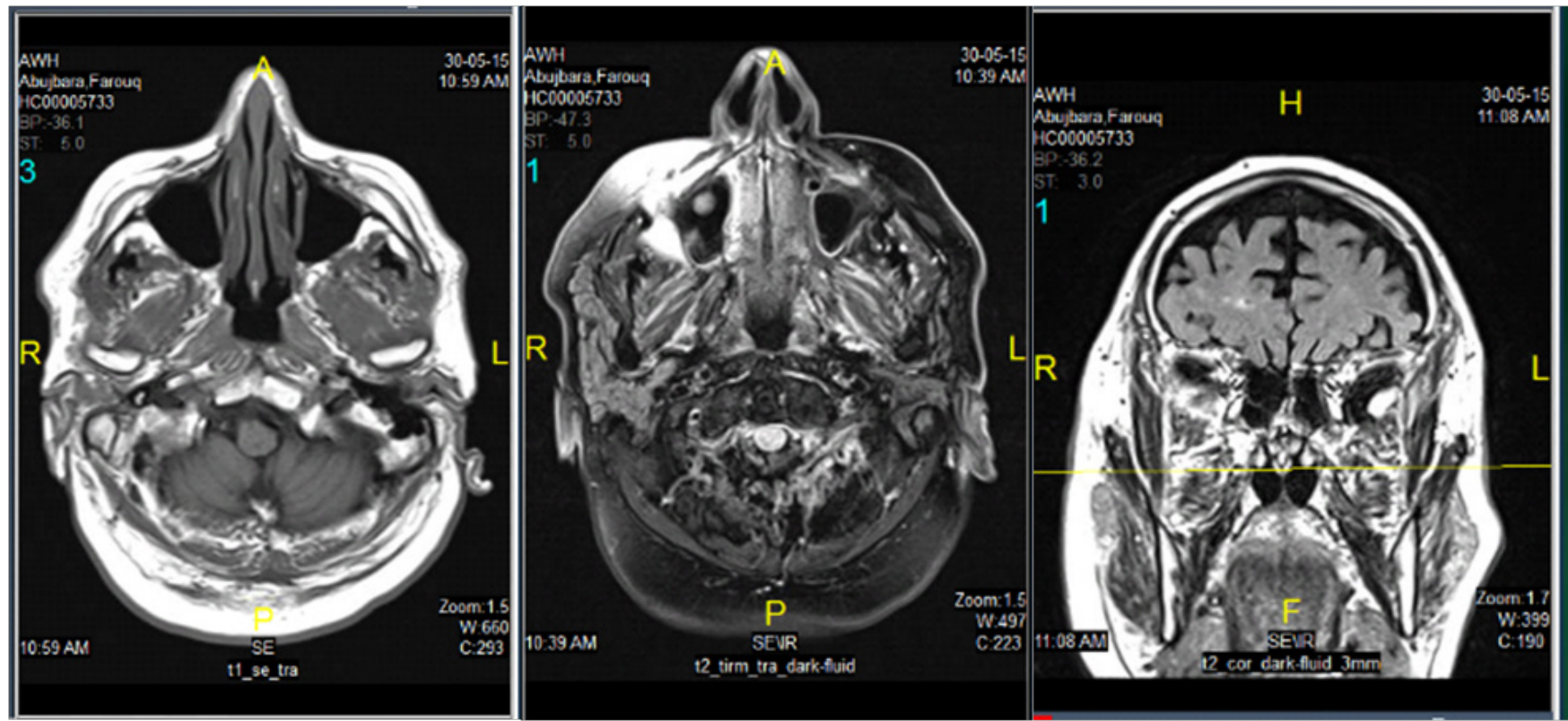

The MRI of the patient show no sign of either degenerative disease or conductive olfactory loss due to obstruction, injury of the olfactory cleft, or sinunasal disease.

Although post-traumatic olfactory loss may be secondary to shearing of olfactory nerve fibers passing through the ethmoidal cribriform plate, contusion of the olfactory bulb and/or frontal lobe. ${ }^{15}$

Data from histological studies of olfactory mucosa from patients with post-traumatic anosmia have shown massive axonal regeneration near the basal membrane, damage to epithelial architecture and loss of peripheral cilia. Natural honey helps in regeneration of tissue via its anti-inflammatory, anti-oxidant, angiogenic effects. This is done via stimulating peripheral blood to draw $\mathrm{B}$ and $\mathrm{T}$ lymphocytes to the mucosal surface and activating phagocytes and monocytes to release cytokines, Tumor necrosis factor- 1 , and IL., ${ }^{1,4}$ The anti-inflammatory action of honey is an essential element in the recovery of olfaction since it enhances circulation and delivers more oxygen and nutrients to help the tissue repair and heal. ${ }^{16,17}$ Honey helps in tissue repair via its stimulatory effect on fibroblastproliferation ${ }^{18}$ and reduction of cellular edema. Furthermore, honey exerts cytoprotective activity on mucosal epithelia as evidenced by histological studies which showed decreased exfoliation of mucosal cells, reduced inflammatory exudates, minimizing mucosal cells and vascular permeability chances.

Although in post-traumatic anosmia systemic corticosteroids are used to reduce possible edema of the central regions, therapeutic options are lacking in the majority of patients suffering from posttraumatic anosmia. ${ }^{6}$ However, patients should be aware of the potential side effects with the prolonged use of systemic corticosteroids. Topical application of Natural honey on the other hand may prove to be an efficacious and a safe alternative to potentially toxic main stream medicine, although the exact mechanism of natural honey still remains unclear. ${ }^{19-26}$ 


\section{Consent}

Written informed consent was obtained from the patient for publication of this case report and any accompanying images. A copy of the written consent is available for review by the Editor-in-Chief of this journal.

\section{Competing interests}

The author declares that they have no competing interests.

\section{Acknowledgments}

None.

\section{Conflict of interest}

The authors report no potential conflicts.

\section{References}

1. Fornazieri MA, Dos Santos CA, Bezerra TFP, et al. Development of normative data for the Brazilian adaptation of the university of pennsylvania smell identification test. Chem Senses. 2015;40(2):141-149.

2. Damm M, Temmel A, Welge Lussen A, et al. Riechstörungen. Epidemiologie und Therapie in Deutschland, Österreich und der Schweiz. HNO. 2004;52(2):112-120.

3. Thomas Getchell V, Costanzo RM, Bartoshuk LM, et al. Head trauma. In Smell and Taste in Health and Disease. In: Getchell TV, et al. editors. Raven Press. 1991. pp. 711-730.

4. Hiroyuki Zusho. Posttraumatic anosmia. Arch Otolaryngol. 1982;108(2):90-92.

5. Smeets MA, Veldhuizen MG, Galle S, et al. Sense of smell disorder and health-related quality of life. Rehabil Psychol. 2009;54(4):404-412.

6. Temmel AF, Quint C, Schickinger Fischer B, et al. Characteristics of olfactory disorders in relation to major causes of olfactory loss. Arch Otolaryngol Head Neck Surg. 2002;128(6):635-641.

7. Simmen D, Briner HR. Olfaction in rhinology-methods of assessing the sense of smell. Rhinology. 2006;44(2):98-101.

8. Pinto JM. Olfaction. Proc Am Thorac Soc. 2011;8(1):46-52.

9. Khalil MI, Sulaiman SA, Boukraa L. Antioxidant properties of honey and its role in preventing health disorder. The Open Nutraceuticals Journal. 2010;3:6-16.

10. Tan HT, Rahman RA, Gan SH, et al. The antibacterial properties of Malaysian tualang honey against wound and enteric microorganisms in comparison to manuka honey. BMC Complement Altern Med. 2009;15:934.

11. Kamaruzaman NA, Sulaiman SA, Kaur G, et al. Inhalation of honey reduces airway inflammation and histopathological changes in a rabbit model of ovalbumin-induced chronic asthma. BMC Complementary and Alternative Medicine. 2014;14:176.

12. Kamaruzaman NA, Sulaiman SA, Kaur G, et al. Inhalation of honey reduces airway inflammation and histopathological changes in a rabbit model of ovalbumin-induced chronic asthma. BMC Complementary and Alternative Medicine. 2014;14:176.

13. Bean A. Investigating the Anti-inflammatory Activity of Honey. University of Waikato: Doctoral Dissertation; 2012.

14. Pieper B. Honey-Based Dressings and Wound Care. J Wound Ostomy Continence Nurs. 2009;36(1):60-66.

15. Kobal G, Hummel T. Olfactory evoked potentials in humans. In Smell and Taste in Health and Disease. Editors: Getchell TV, et al. Raven Press. $1991 ; 255-275$.

16. Abuharfeil N, Al Oran R, Abo Shehada M. The effect of bee honey on the proliferative activity of human B- and T-lymphocytes and the activity of phagocytes. Food Agric Immunol. 1999;11(2):169-177.

17. Al Jadi AM, Kanyan Enchang F, Mohd Yusoff K. The effect of Malaysian honey and its major components on the proliferation of cultured fibroblasts. Turk J Med Sci. 2014;44(5):733-740.

18. Nur Jannah MH, Mahmood AA, Sidik K, et al. Cytoprotective effects of honey in combination with aqueous and ethanol extracts from Chromolaena odorata L (Eupatorium odoratum) in rats. Journal of Health and Translational Medicine. 2006;9(1):7-13.

19. Nordin S, Bramerson A. Complaints of olfactory disorders: epidemiology, assessment and clinical implications. Curr Opin Allergy Clin Immunol. 2008;8(1):10-15.

20. Reden J, Mueller A, Mueller C, et al. Recovery of olfactory function following closed head injury or infections of the upper respiratory tract. Arch Otolaryngol Head Neck Surg. 2006;132(3):265-269.

21. Sumner D. Post-traumatic anosmia. Brain. 1964;87(1):107-120.

22. Hummel T, Sekinger B, Wolf SR, et al. Sniffin' sticks: olfactory performance assessed by the combined testing of odor identification, odor discrimination and olfactory threshold. Chem Senses. 1997;22(1):39-52.

23. Hummel T, Kobal G, Gudziol H, et al. Normative data for the 'Sniffin' Sticks' including tests of odor identification, odor discrimination, and olfactory thresholds: an upgrade based on a group of more than 3,000 subjects. Eur Arch Otorhinolaryngol. 2007;264(3):237-243.

24. Delank KW, Fechner G. Zur Pathophysiologie der posttraumatischen Riechstorung. Laryngorhinootologie. 1996;75:154-159.

25. Jafek BW, Eller PM, Esses BA, et al. Post-traumatic anosmia. Ultrastructural correlates. Arch Neurol. 1989;46(3):300-304.

26. Santos DV, Reiter ER, Costanzo RM et al. Hazardous events associated with impaired olfactory function. Arch Otolaryngol Head Neck Surg. 2004;130(3):317-319. 